\title{
A last millennium perspective on North Atlantic \\ variability: exploiting synergies between models \\ and proxy data
}

doi: 10.22498/pages.25.1.61

\section{Pablo Ortega ${ }^{1}$, Jon Robson ${ }^{1}$, Paola Moffa-Sanchez², David Thornalley², Didier Swingedouw ${ }^{4}$}

\author{
1 NCAS-Climate, Department of Meteorology, University of Reading, Reading, UK \\ 2 School of Earth and Ocean Sciences, Cardiff University, Cardiff, UK \\ 3 Department of Geography, University College London, London, UK \\ 4 EPOC/CNRS, Université de Bordeaux, Bordeaux, France
}

\section{Introduction}

The North Atlantic is a key region for decadal prediction as it has experienced significant multi-decadal variability over the observed period. This variability, which is thought to be intrinsic to the region, can potentially modulate, either by amplifying or mitigating, the global warming signal from anthropogenic greenhouse emissions. For example, studies suggest that the North Atlantic contributed to the recent hiatus period between 1998 and 2012, by triggering an atmospheric response which impacted on the eastern tropical Pacific (e.g. McGregor et al., 2014). The subpolar North Atlantic is also a major $\mathrm{CO}_{2}$ sink, and therefore of great importance for the global carbon cycle (Perez et al., 2013).

One of the key players in the North Atlantic region is the Atlantic Meridional Overturning Circulation (AMOC), which is associated with sinking due to deep water formation in the Labrador and Nordic Seas. The AMOC is the primary control of the poleward heat transport in the Atlantic region. Therefore, the AMOC is associated with important climate impacts, and plays an active role in various feedback mechanisms with, for example, sea ice (Mahajan et al., 2011) and the atmospheric circulation (Gastineau and Frankignoul, 2012). The AMOC has exhibited abrupt variations in the past (e.g. the last glacial period, Rahmstorf, 2002) and could experience a major slowdown in the future due to the combined effect of surface warming and Greenland ice sheet melting on deep water formation (Bakker et al., 2016). The possibility of such a shutdown has stimulated considerable international efforts to observe and reconstruct the past AMOC changes. Only by understanding its natural variability will we be able to detect and anticipate an anthropogenic impact on the AMOC.

Decadal modulations are also found in other large-scale modes of climate variability, such as the North Atlantic Oscillation (NAO) (Stephenson et al., 2000), the Subpolar Gyre strength (SPG) (Häkkinen and Rhines, 2004) and the Atlantic Multidecadal Variability (AMV) (Enfield et al., 2001), which have all been linked with widespread climate impacts over the surrounding continents. Modelling studies suggest that all these modes interact with the AMOC (Gastineau and Frankignoul, 2012; Hátún et al., 2005; Knight et al., 2005) but the exact interrelationships are complex and remain to be disentangled. Also to be determined are the underlying mechanisms responsible for the decadal and centennial AMOC modulations, with different climate models showing different key drivers (Menary et al., 2015a). Similarly, the exact impact of the natural external forcings (e.g. volcanic aerosols, solar irradiance) on the variability of these different largescale climate modes still remains unclear.

\section{A unique opportunity to deepen our understanding} The study of the last millennium climate provides us with an ideal framework to investigate natural climate variability and associated mechanisms within the North Atlantic. It is particularly interesting because it provides a long-term context of naturally forced variability which is useful (i) to assess whether current or future changes in these variables are unprecedented, (ii) to robustly test the effects of natural forcings on their variability (e.g. by increasing the sample size of major volcanic events), and (iii) to better characterise the typical timescales of the key variables at play (e.g. AMOC, AMV, SPG).

The availability of data to undertake these analyses is rapidly increasing thanks to joint efforts from the modelling and paleoclimate data communities. The Paleoclimate Modelling Intercomparison Project (PMIP) is now entering its fourth phase, and includes a set of coordinated "tier 1 " experiments for the last millennium (Jungclaus et al., 2016), with all models using, for the first time, the same "default" external forcing configuration. Additional sensitivity experiments to explore the uncertainty in external forcings are also envisaged. The ultimate purpose of this exercise is to evaluate 
the skill of models against well-documented climatic epochs, in order to reduce the uncertainty for future climate projections. Additionally, the OCEAN2K initiative within the PAGES2k network has prepared a first sea surface temperature (SST) synthesis dataset (McGregor et al., 2015), including 29 peer-reviewed and publicly available reconstructions from marine-archives in the Atlantic ocean, all of them covering, at least partly, the last 2000 years. Phase 2 of the OCEAN2K initiative aims to advance this field by addressing different topics, specifically two working groups will compile and study paleoceanographic reconstructions related to the dynamical overturning changes in the North Atlantic, one specifically focused on the proxy data, and the other in model-data comparisons.

\section{Our current knowledge of the last millennium from observations and paleoclimate records}

Because of the dynamic and large-scale nature of the AMOC, robust observations of its variability require extensive (and costly) measurement arrays. The first continuous measurements of its strength date back to 2004 , when the RAPID observing array at $26^{\circ} \mathrm{N}$ was deployed. The first decade of observations exhibits a weakening of about 0.5 Sv per year (Smeed et al., 2014). An obvious question is whether this decline is linked to the effect of global warming or instead reflects natural multi-decadal variability. Different approaches have been considered to reconstruct the AMOC changes back in time and give a longer context to this trend; however, the connection of these indirect estimates with the AMOC can present important uncertainties, which can contribute to conflicting conclusions. For example, Rahmstorf et al. (2015) uses AMOC covariances with SSTs to produce an AMOC reconstruction for the last millennium (Fig. 1a). A drawback of this reconstruction is that it employs a gridded surface temperature reconstruction (Mann et al., 2008) mostly based on indirect proxy evidence from continental areas. This index suggests that the AMOC has been weakening since the beginning of the $20^{\text {th }}$ century, which Rahmstorf et al (2015) suggest is a consequence of Greenland ice sheet melting. A similar centennial trend is found in Dima and Lohmann (2010), which uses SST observations to make inferences about the large-scale circulation. However, other studies based on different techniques contradict these results. For instance, two independent reconstructions of the ocean circulation based on sea level data (McCarthy et al., 2015) and deep Labrador Sea densities (Robson et al., 2016) show no major long-term trends during the industrial period.

On longer time-scales, rather than aiming to reconstruct the AMOC as a whole, investigation of individual surface and deep components of the AMOC may be more easily realized. Proxy-based reconstructions of the Florida Current transport (Lund et al., 2006) and the surface ocean circulation near the North Icelandic shelf (Wanamaker et al., 2012) are both suggestive of a strengthening of the AMOC during the last two centuries (Fig. 1b), following a minimum during the cold interval termed the Little Ice Age (LIA). These results are therefore also in stark contrast with the Rahmstorf et al. (2015) reconstruction. Reconstructions of the vigour of the Nordic Seas Overflows (Fig. 1c) show multi-centennial changes across the last millennium. Interestingly, there is evidence of a potential anti-phase relationship between the overflows East and West of Iceland, with the Denmark Strait Overflow Water (DSOW) strengthening when the Iceland Scotland Overflow Water (ISOW) is weaker, and vice versa (Moffa-Sanchez et al. 2015). This configuration suggests a constant flow of deep dense waters over the Greenland Scotland Ridge through the last millennium. If we assume that the AMOC does exhibit significant centennial variability, the inferred near-constancy of the Nordic Overflows possibly implicates changes in Labrador Sea Water formation as a key driver of centennial AMOC variability as suggested by Moffa-Sanchez et al. (2014b) for the LIA, which would parallel its important role in recent decadal changes.

We turn now our attention to other major contributors to North Atlantic climate variability in the last millennium. The role of the atmosphere has been invoked to explain another important centennial-scale climate event: the Medieval Climate Anomaly (MCA). A bi-proxy NAO reconstruction (Trouet et al., 2009) shows persistent strong positive phases during this period, followed by a shift towards more negative phases that could have partly contributed to the MCA-LIA transition (Fig. 1d, light green line). However, these remarkable multi-centennial changes are less evident in a more recent annuallyresolved reconstruction based on multiple proxy records (Fig. 1d, dark green line, Ortega et al., 2015). Of relevance for prediction purposes, this recent reconstruction suggests that volcanic aerosols can induce positive NAO phases peaking 2 years after the eruptions. Mid-sized volcanic eruptions can also impact the ocean and act as a pacemaker of the intrinsic oceanic variability, as shown for two independent proxy reconstructions of the AMV and the AMOC-driven changes in the nutrient supply North of Iceland (Swingedouw et al., 2015). Likewise, decadal climate fluctuations can be associated with, for example, the occurrence of Great Salinity Anomalies (Belkin et al., 1998). All of these processes (forced and unforced) can have different impacts on the variability of the major large-scale ocean modes in the North Atlantic. Indeed, the available reconstructions highlight prominent centennial changes in the AMOC (Fig. 1a), multidecadal changes in the AMV (Fig. 1e) and decadal changes in the SPG strength (Fig. 1f).

Disentangling the interplay between these different modes of variability and the wider climate system is still not possible due to the uncertainties and sparsity of current reconstructions. Yet, paleoclimatology is a growing field and the spatial distribution and number 


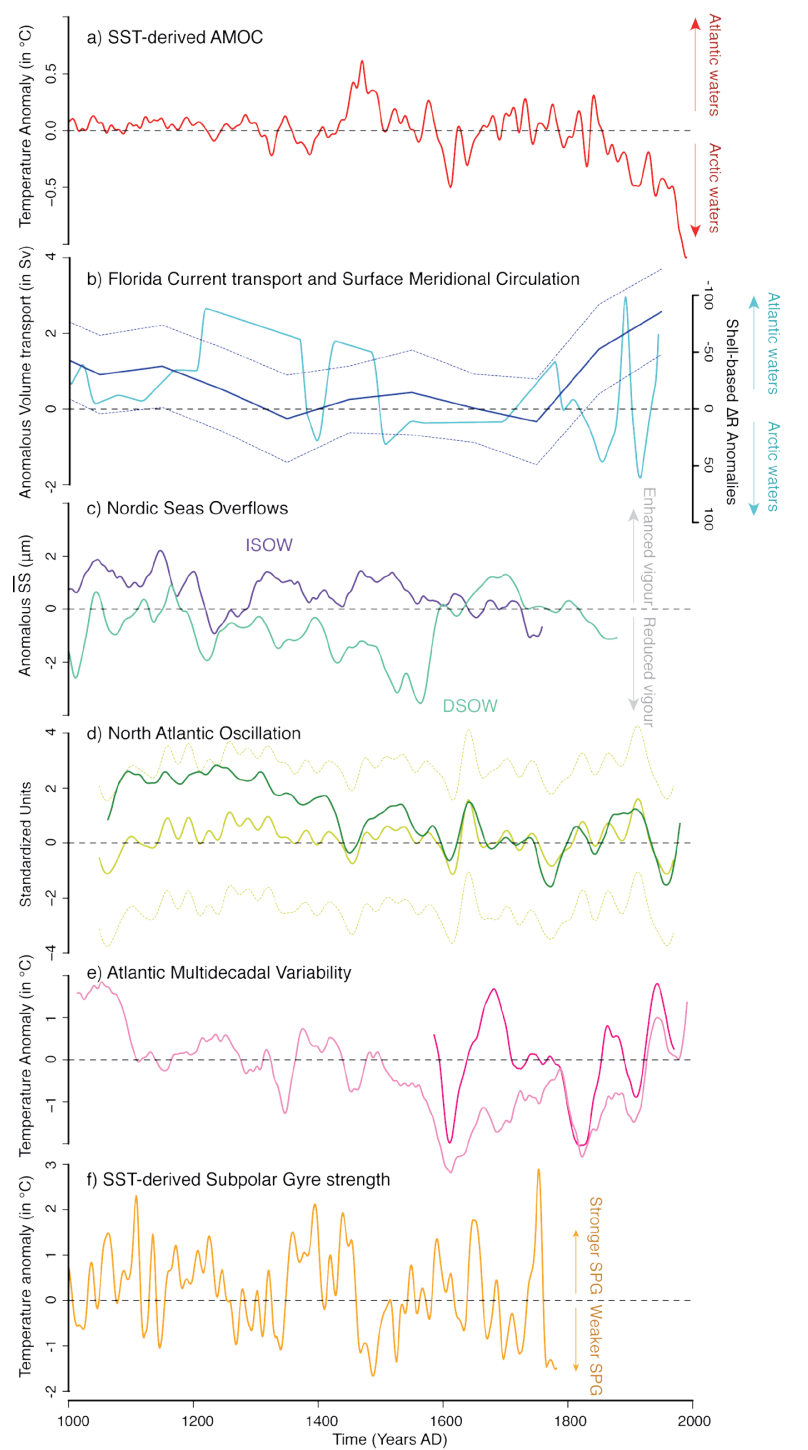

Figure 1: Last-millennium paleo-climate evidence for the North Atlantic: a) Surface temperature-derived AMOC reconstruction (Rahmstorf et al., 2015), b) Estimates of the Florida current (blue line; Lund et al., 2006) and northwardflowing surface transport across the North-Icelandic shelf (light blue line; Wanamaker et al., 2012), c) sortable silt )-derived Denmark Strait Overflow Water (DSOW) and Iceland-Scotland Overflow Water (ISOW) flow speed (MoffaSanchez et al., 2015), d) reconstructed NAO evolution (dark green line, Trouet et al., 2009; light green lines, Ortega et al., 2015), e) estimates of AMV (light pink line, Mann et al., 2009; dark pink line Gray et al., 2004) and f) SST-derived changes in the Subpolar Gyre Strength (Moffa-Sánchez et al., 2014a). All panels show anomalous values with respect to the common period 1572-1787. All data were decadally smoothed, except for the Florida Current record, which is centennially resolved, and the NAO and overflow reconstructions, instead smoothed at 30 years to better highlight the multi-decadal changes.

of high-resolution proxy records is continuously increasing, especially for the last millennium, which should soon allow more reliable reconstructions. In particular, the production of new subdecadally resolved marine proxies is necessary to provide first-hand insights about the past changes in the ocean. Until now, these have been largely inferred from continental records and therefore rely on atmospheric teleconnections that are still not totally understood. In addition, extending the current network of terrestrial records is also important to better constrain the concomitant atmospheric changes and continental impacts.

\section{Insights from climate models}

Climate models provide a complementary source of information for the last millennium, allowing us to test different hypotheses, such as the external forcing conditions, and their effect on the major climate excursions (e.g. MCA, LIA, industrial global warming). Their horizontal and vertical resolution, as well as the representation of key physical processes (e.g. ocean eddies, aerosol-cloud and sea-ice interactions), are being continuously improved, offering unique access to the complexity of the climate system. One common aspect to most atmosphere-ocean general circulation models (AOGCMs) is that they naturally generate decadal fluctuations in the North Atlantic under fixed external forcing conditions. However, there is considerable diversity in the mechanisms that lead to such decadal variability. For example, studies with idealized models suggest that multi-decadal oscillations (particularly linked to the AMV) can emerge in the absence of interactive ocean dynamics (Clement et al., 2015; Srivastava and DelSole, 2017). More generally, the preferential timescale of the internal variability is associated with ocean adjustment processes that are strongly model dependent (Menary et al., 2015a), suggesting an important sensitivity to model biases (Menary et al., 2015b). Encouragingly, a multi-model comparison in control simulations $(\mathrm{Ba}$ et al., 2014) reports reasonable consistency in terms of the major interactions in the North Atlantic; 8 out of 10 models show a close link between AMV and the AMOC and most of them exhibit a lagged relationship between the SPG changes and those in the AMOC. However, none of the models in Ba et al. (2014) appear to support a significant relationship between the AMOC and the NAO at decadal timescales, a result inconsistent with other studies supporting a driving role of the NAO on decadal AMOC variability (e.g. Ortega et al., 2011; Mecking et al., 2014). Ba et al. (2014) also noted that salinity-driven density anomalies seem to play a dominant role in North Atlantic convection, and therefore, on the AMOC. Yet, the salinity contribution might be over-represented due to important cold model biases, which could potentially compromise the realism of their described interrelationships.

To date, only a limited number of studies have systematically assessed the effect of external forcings on these modes of climate variability. For example, GómezNavarro and Zorita (2013) found no evidence of coherent changes in NAO variability across a large ensemble of last millennium AOGCM simulations, suggesting that all NAO variability was internally driven. This, however, might be 
due to well-known limitations in the previous generation of AOGCMs (PMIP3 and older), either due to a coarse representation of the stratosphere, or to a simplistic implementation of the radiative forcings. Indeed, the CNRM-CM5 model, which has a highly resolved stratosphere, and was not included in the previous analysis, shows a consistent strong positive NAO response to volcanic eruptions. Volcanic forcing is also found to excite an heterogeneous range of responses of both the AMOC and AMV, as shown for several last millennium simulations in Swingedouw et al. (2017). Thus, in light of these large model uncertainties, proxy records provide essential information to assess the degree of realism of models, and thus identify the most reliable ones.

\section{Combining model and paleoclimate data}

There are multiple ways in which model simulations and proxy reconstructions can benefit from each other. Besides the obvious use of paleoclimate records as a reference benchmark for climate models, models can also prove extremely useful (i) for the climatic interpretation of proxies (e.g., Bakker et al., 2015), (ii) to evaluate the validity of different reconstruction techniques (e.g., Moreno-Chamarro et al., 2017), and (iii) to guide future paleo-oceanographic efforts to new regions and variables with relevant climate information.

The latter point can be addressed with model-derived ocean fingerprints (Zhang, 2008), highlighting covariability between the large-scale climate modes and other more easily observed climate variables. These, however, need to be considered with caution, as important differences can emerge from the various models, and also at different timescales (Muir and Fedorov, 2015). In Fig. 2 we explore the potential of ocean fingerprints for the identification of suitable proxies to produce separate distinct reconstructions of the AMV, AMOC and SPG strength. The figure depicts the correlation of the simulated SST fields with the large-scale variability (AMOC, AMV, SPG) in two 300-yr high-resolution AOGCM control experiments with different ocean and atmosphere components. All data is decadally smoothed with 10 -year running means to focus on the multidecadal co-variability. Interestingly, despite some apparent differences between the models, robust features are also discerned. The impact of the AMOC on SSTs is most pronounced when the AMOC leads by 6 years, with both simulations showing an area of maximum correlations in the eastern SPG, for which some SST-sensitive proxy records are available (green dots and yellow stars in Fig. 2). By contrast, correlations with the AMV show a larger-scale structure that extends to the subtropical North Atlantic. Thus, the addition of existing proxy records near West Africa and the Brazilian coast could help to disentangle AMV variability from that of the AMOC. As for the SPG strength, both models exhibit a coherent SST dipole between the Gulfstream and the Gulf of Saint Lawrence, which could have encouraging potential for reconstruction purposes due to the high availability of proxy records in both regions.
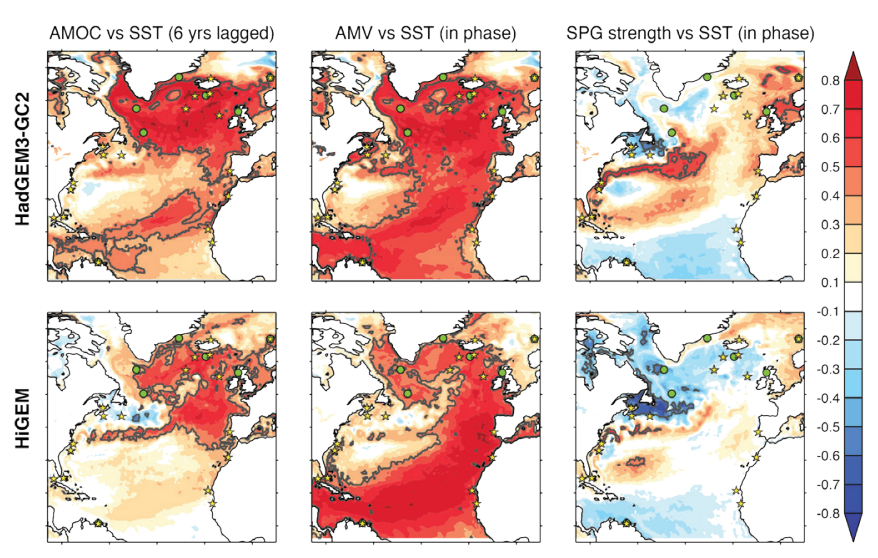

Figure 2: Spatial correlations between a selection of North Atlantic climate indices and the SST fields in two 300-yr long preindustrial control runs with HadGEM3-GC2 (Ortega et al., 2016; top) and HiGEM (Shaffrey et al., 2009; bottom). All data were low-pass filtered at 10 years to highlight the decadal variability. In-phase correlations are shown for the AMV and SPG strength indices. For the AMOC index, SSTs are delayed by 6 years (the lag with maximum correlations). Significant values at the 95\% confidence level are highlighted with thick grey contours. Yellow stars indicate the location of the SST reconstructions compiled by the OCEAN2K community (McGregor et al., 2015) and green circles the position of other temperaturerecordsalsoavailable(Risebrobakkenetal.,2003; Cage and Austin, 2010; Wurtzel et al., 2013; Moffa-Sánchez et al., 2014a,b; Hoogakker et al., 2015; Miettinen et al., 2015).

Although the comparison of the co-variability patterns in these two high-resolution models is largely consistent, broader multi-model comparisons are still necessary to evaluate which fingerprints are robust. Coarser lastmillennium simulations are also required in order to test if and how the inclusion of forced centennial variability impacts the simulated covariances - we suspect that it does, since previous studies with transient simulations exhibit a clear "warming hole" SST response to long-term forced AMOC changes (Drijfhout et al., 2012; Rahmstorf et al., 2015), not present in Fig. 2. The multi-model assessment could be extended to other AMOC-sensitive climate variables that are well captured by proxies, such as sea level height. As an alternative to the use of ocean fingerprints, proxies of deep-ocean flow speed, based on sortable silt measurements, and $\delta^{13} \mathrm{C}$ records may also be used to infer past changes in the deep ocean circulation. Although informative, the interpretation of some of these proxies with regards to AMOC is not straightforward, carbon-isotope enabled climate models highlight that $\delta^{13} \mathrm{C}$ variability cannot always be interpreted in terms of changing AMOC (Bakker etal., 2015; Blaschek etal., 2015). Likewise, the link of local flow speed to the largescale circulation is not always obvious, and sholud be supported through the use of high-resolution climate models, and where possible, with related observational data. 
A final approach to combining model simulations and paleoclimate records to better constrain past climate evolution is the use of data assimilation techniques. A first attempt has been made with a simplified climate model, although this showed limited reliability in the North Atlantic ocean (Goosse et al., 2010). Recently, the launch of a last millennium climate reanalysis (LMR) project (Hakim et al., 2016) has fostered research on this topic, and will hopefully lead soon to the first AOGCM-based reanalysis covering the last millennium, providing key information about both externally-forced and internallydriven changes in the North Atlantic.

The latest advances by the paleoclimate and modelling communities thus present us with a unique opportunity to further our understanding of the main processes that shaped climate variability in the North Atlantic over the last millennium. To this end, exploiting model-data synergies will be essential because it will help to improve reconstructions, and to identify the most reliable climate model simulations.

\section{Acknowledgements}

We are grateful to David Lund (University of Connecticut) for sharing the data of the Florida Current reconstruction with us, and to all the researchers that made their data available online. The GC2 model data used in this study was kindly provided to us by the UK Met Office, which keeps the ownership rights under Crown Copyright. Finally, we acknowledge the support from NERC (project DYNAMOC, NE/ M005127/1) and ANR (HAMOC project, ANR-13-BS06-0003).

\section{References}

Ba, J., Keenlyside, N.S., Latif, M., Park, W., Ding, H., Lohmann, K., Mignot, J., Menary, M., Otterå, O.H., Wouters, B., Salas y Melia, D., Oka, A., Bellucci, A., Volodin, E., 2014. A multi-model comparison of Atlantic multidecadal variability. Clim. Dyn. 43, 2333-2348. doi:10.1007/ s00382-014-2056-1

Bakker, P., Govin, A., Thornalley, D.J.R., Roche, D.M., Renssen, H., 2015. The evolution of deep-ocean flow speeds and $\delta 13 \mathrm{C}$ under large changes in the Atlantic overturning circulation: Toward a more direct modeldata comparison. Paleoceanography 30, 95-117. doi:10.1002/2015PA002776

Bakker, P., Schmittner, A., Lenaerts, J.T.M., Abe-Ouchi, A., Bi, D., van den Broeke, M.R., Chan, W.-L., Hu, A., Beadling, R.L., Marsland, S.J., Mernild, S.H., Saenko, O.A., Swingedouw, D., Sullivan, A., Yin, J., 2016. Fate of the Atlantic Meridional Overturning Circulation: Strong decline under continued warming and Greenland melting. Geophys. Res. Lett. 43, 12,212-252,260. doi:10.1002/2016GL070457

Belkin, I.M., Levitus, S., Antonov, J., Malmberg, S.-A., 1998. 'Great Salinity Anomalies' in the North Atlantic. Prog.
Oceanogr. 41, 1-68. doi:http://dx.doi.org/10.1016/ S0079-6611(98)00015-9

Blaschek, M., Renssen, H., Kissel, C., Thornalley, D., 2015. Holocene North Atlantic Overturning in an atmosphereocean-sea ice model compared to proxy-based reconstructions 1503-1524.

doi:10.1002/2015PA002828.Received

Cage, A.G., Austin, W.E.N., 2010. Marine climate variability during the last millennium: The Loch Sunart record, Scotland, UK. Quat. Sci. Rev. 29, 1633-1647. doi:http:// dx.doi.org/10.1016/j.quascirev.2010.01.014

Clement, A., Bellomo, K., Murphy, L.N., Cane, M.A., Mauritsen, T., Rädel, G., Stevens, B., 2015. The Atlantic Multidecadal Oscillation without a role for ocean circulation. Science (80-. ). 350, 320-324.

Dima, M., Lohmann, G., 2010. Evidence for Two Distinct Modes of Large-Scale Ocean Circulation Changes over the Last Century. J. Clim. 23, 5-16. doi:10.1175/2009JCLI2867.1

Drijfhout, S., van Oldenborgh, G.J., Cimatoribus, A., 2012. Is a Decline of AMOC Causing the Warming Hole above the North Atlantic in Observed and Modeled Warming Patterns? J. Clim. 25, 8373-8379. doi:10.1175/ JCLI-D-12-00490.1

Enfield, D.B., Mestas-nuñez, A.M., Trimble, P.J., 2001. The Atlantic Multidecadal Oscillation and its Relationship to Rainfall and River Flows in the Continental U . S . A research article resubmitted to Geophysical Research Letters. Atlantic 28, 2077-2080.

Gastineau, G., Frankignoul, C., 2012. Cold-season atmospheric response to the natural variability of the Atlantic meridional overturning circulation. Clim. Dyn. 39, 37-57. doi:10.1007/s00382-011-1109-y

Gómez-Navarro, J.J., Zorita, E., 2013. Atmospheric annular modes in simulations over the past millennium: No longterm response to external forcing. Geophys. Res. Lett. 40, 3232-3236. doi:10.1002/grl.50628

Goosse, H., Crespin, E., de Montety, A., Mann, M.E., Renssen, H., Timmermann, A., 2010. Reconstructing surface temperature changes over the past 600 years using climate model simulations with data assimilation. J. Geophys. Res. Atmos. 115, n/a-n/a. doi:10.1029/2009JD012737

Gray, S.T., Graumlich, L.J., Betancourt, J.L., Pederson, G.T., 2004. A tree-ring based reconstruction of the Atlantic Multidecadal Oscillation since 1567 A.D. Geophys. Res. Lett. 31, L12205. doi:10.1029/2004GL019932

Hakim, G.J., Emile-Geay, J., Steig, E.J., Noone, D., Anderson, 
D.M., Tardif, R., Steiger, N., Perkins, W.A., 2016. The last millennium climate reanalysis project: Framework and first results. J. Geophys. Res. Atmos. 121, 6745-6764. doi:10.1002/2016JD024751

Häkkinen, S., Rhines, P.B., 2004. Decline of subpolar North Atlantic circulation during the 1990s. Science 304, 555-559. doi:10.1126/science.1094917

Hátún, H., Sandø, A.B., Drange, H., Hansen, B., Valdimarsson, H., 2005. Influence of the Atlantic subpolar gyre on the thermohaline circulation. Science (80). 309, 1841-1844.

Hoogakker, B.A.A., McCave, I.N., Elderfield, H., HillaireMarcel, C., Simstich, J., 2015. Holocene climate variability in the Labrador Sea. J. Geol. Soc. 172, 272-277. doi:10.1144/jgs2013-097

Jackson, L.C., Peterson, K.A., Roberts, C.D., Wood, R.A., 2016. Recent slowing of Atlantic overturning circulation as a recovery from earlier strengthening. Nat. Geosci 9, 518-522.

Jungclaus, J.H., Bard, E., Baroni, M., Braconnot, P., Cao, J., Chini, L.P., Egorova, T., Evans, M., González-Rouco, J.F., Goosse, H., Hurtt, G.C., Joos, F., Kaplan, J.O., Khodri, M., Klein Goldewijk, K., Krivova, N., LeGrande, A.N., Lorenz, S.J., Luterbacher, J., Man, W., Meinshausen, M., Moberg, A., Nehrbass-Ahles, C., Otto-Bliesner, B.I., Phipps, S.J., Pongratz, J., Rozanov, E., Schmidt, G.A., Schmidt, H., Schmutz, W., Schurer, A., Shapiro, A.I., Sigl, M., Smerdon, J.E., Solanki, S.K., Timmreck, C., Toohey, M., Usoskin, I.G., Wagner, S., Wu, C.-Y., Yeo, K.L., Zanchettin, D., Zhang, Q., Zorita, E., 2016. The PMIP4 contribution to CMIP6 - Part 3: the Last Millennium, Scientific Objective and Experimental Design for the PMIP4 past1000 simulations. Geosci. Model Dev. Discuss. 2016, 1-34. doi:10.5194/ gmd-2016-278

Knight, J.R., Allan, R.J., Folland, C.K., Vellinga, M., Mann, M.E., 2005. A signature of persistent natural thermohaline circulation cycles in observed climate. Geophys. Res. Lett. 32, 1-4. doi:10.1029/2005GL024233

Lund, D.C., Lynch-Stieglitz, J., Curry, W.B., 2006. Gulf Stream density structure and transport during the past millennium. Nature 444, 601-604. doi:10.1038/ nature 05277

Mahajan, S., Zhang, R., Delworth, T.L., 2011. Impact of the Atlantic Meridional Overturning Circulation (AMOC) on Arctic Surface Air Temperature and Sea Ice Variability. J. Clim. 24, 6573-6581. doi:10.1175/2011JCLI4002.1

Mann, M.E., Zhang, Z., Hughes, M.K., Bradley, R.S., Miller, S.K., Rutherford, S., Ni, F., 2008. Proxy-based reconstructions of hemispheric and global surface temperature variations over the past two millennia. Proc. Natl. Acad. Sci. U. S. A. 105, 13252-13257. doi:10.1073/ pnas.0805721105

Mann, M.E., Zhang, Z., Rutherford, S., Bradley, R.S., Hughes, M.K., Shindell, D., Ammann, C., Faluvegi, G., Ni, F., 2009. Global signatures and dynamical origins of the Little Ice Age and Medieval Climate Anomaly. Science 326, 12561260. doi:10.1126/science. 1177303

McCarthy, G.D., Haigh, I.D., Hirschi, J.J.-M., Grist, J.P., Smeed, D. a., 2015. Ocean impact on decadal Atlantic climate variability revealed by sea-level observations. Nature 521, 508-510. doi:10.1038/nature 14491

McGregor, S., Timmermann, A., Stuecker, M.F., England, M.H., Merrifield, M., Jin, F.-F., Chikamoto, Y., 2014. Recent Walker circulation strengthening and Pacific cooling amplified by Atlantic warming. Nat. Clim. Chang. 4, 888892.

McGregor, H. V, Evans, M.N., Goosse, H., Leduc, G., Martrat, B., Addison, J.A., Mortyn, P.G., Oppo, D.W., Seidenkrantz, M.-S., Sicre, M.-A., Phipps, S.J., Selvaraj, K., Thirumalai, K., Filipsson, H.L., Ersek, V., 2015. Robust global ocean cooling trend for the pre-industrial Common Era. Nat. Geosci 8, 671-677.

Mecking, J. V., Keenlyside, N.S., Greatbatch, R.J., 2014. Stochastically-forced multidecadal variability in the North Atlantic: A model study. Clim. Dyn. 43, 271-288. doi:10.1007/s00382-013-1930-6

Menary, M.B., Hodson, D.L.R., Robson, J.I., Sutton, R.T., Wood, R.A., 2015. A Mechanism of Internal Decadal Atlantic Ocean Variability in a High-Resolution Coupled Climate Model. J. Clim. 28, 7764-7785. doi:10.1175/ JCLI-D-15-0106.1

Menary, M.B., Hodson, D.L.R., Robson, J.I., Sutton, R.T., Wood, R.A., Hunt, J.A., 2015. Exploring the impact of CMIP5 model biases on the simulation of North Atlantic decadal variability. Geophys. Res. Lett. 42, 5926-5934. doi:10.1002/2015GL064360

Miettinen, A., Divine, D. V, Husum, K., Koç, N., Jennings, A., 2015. Exceptional ocean surface conditions on the SE Greenland shelf during the Medieval Climate Anomaly. Paleoceanography 30, 1657-1674. doi:10.1002/2015PA002849

Moffa-Sánchez, P., Born, A., Hall, I.R., Thornalley, D.J.R., Barker, S., 2014a. Solar forcing of North Atlantic surface temperature and salinity over the past millennium. Nat. Geosci 7, 275-278. doi:10.1038/ngeo2094

Moffa-Sánchez, P., Hall, I.R., Barker, S., Thornalley, D.J.R., Yashayaev, I., 2014b. Surface changes in 
the eastern Labrador Sea around the onset of the Little Ice Age. Paleoceanography 29, 160-175. doi:10.1002/2013PA002523

Moffa-Sanchez, P., Hall, I.R., Thornalley, D.J.R., Barker, S., Stewart, C., 2015. Changes in the strength of the Nordic Seas Overflows over the past 3000 years. Quat. Sci. Rev. 123, 134-143. doi:10.1016/j.quascirev.2015.06.007

Moreno-Chamarro, E., Ortega, P., González-Rouco, F., Montoya, M., 2017. Assessing reconstruction techniques of the Atlantic Ocean circulation variability during the last millennium. Clim. Dyn. 48, 799-819. doi:10.1007/ s00382-016-3111-x

Muir, L.C., Fedorov, A. V, 2015. How the AMOC affects ocean temperatures on decadal to centennial timescales: the North Atlantic versus an interhemispheric seesaw. Clim. Dyn. 45, 151-160. doi:10.1007/s00382-014-2443-7

Ortega, P., Hawkins, E., Sutton, R., 2011. Processes governing the predictability of the Atlantic meridional overturning circulation in a coupled GCM. Clim. Dyn. 37, 1771-1782. doi:10.1007/s00382-011-1025-1

Ortega, P., Lehner, F., Swingedouw, D., Masson-Delmotte, V., Raible, C.C., Casado, M., Yiou, P., 2015. A model-tested North Atlantic Oscillation reconstruction for the past millennium. Nature 523, 71-4. doi:10.1038/nature14518

Ortega, P., Robson, J.I., Sutton, R.T., Martins, A., 2016. Mechanisms of decadal variability in the Labrador Sea and the wider North Atlantic in a high-resolution climate model. Clim. Dyn. Published Online.

Perez, F. F., H. Mercier, M. Vazquez-Rodriguez, P. Lherminier, A. Velo, P. C. Pardo, G. Roson, and A. F. Rios (2013), Atlantic Ocean $\mathrm{CO}_{2}$ uptake reduced by weakening of the meridional overturning circulation, Nat. Geosci. 6, 146-152.

Rahmstorf, S., 2002. Ocean circulation and climate during the past 120,000 years. Nature 419, 207-214. doi:10.1038/nature01090

Rahmstorf, S., Box, J.E., Feulner, G., Mann, M.E., Robinson, A., Rutherford, S., Schaffernicht, E.J., 2015. Exceptional twentieth-century slowdown in Atlantic Ocean overturning circulation. Nat. Clim. Chang. 5, 475-480. doi:10.1038/nclimate2554

Risebrobakken, B., Jansen, E., Andersson, C., Mjelde, E., Hevrøy, K., 2003. A high-resolution study of Holocene paleoclimatic and paleoceanographic changes in the Nordic Seas. Paleoceanography 18, 1017. doi:10.1029/2002PA000764

Robson, J., Ortega, P., Sutton, R., 2016. A reversal of climatic trends in the North Atlantic since 2005. Nat. Geosci. 9, 513-517.

Shaffrey, L., Stevens, I., Norton, W.A., Roberts, M.J., Vidale, P.L., Harle, J.D., Jrrar, A., Stevens, D.P., Woodage, M.J., Demory, M.E., Donners, J., Clark, D.B., Clayton, A., Cole, J.W., Wilson, S.S., Connolley, W.M., Davi, T.M., Martin, G.M., 2009. U.K. HiGEM: The New U.K. HighResolution Global Environment Model-Model Description and Basic Evaluation. J. Clim. 22, 1861-1896. doi:10.1175/2008JCLI2508.1

Smeed, D.A., McCarthy, G., Cunningham, S.A., FrajkaWilliams, E., Rayner, D., Johns, W.E., Meinen, C.S., Baringer, M.O., Moat, B.I., Duchez, A., Bryden, H.L., 2014. Observed decline of the Atlantic meridional overturning circulation 2004 to 2012. Ocean. Sci. 10, 29-38. doi:10.5194/os-1029-2014

Srivastava, A., DelSole, T., 2017. Decadal predictability without ocean dynamics. Proc. Natl. Acad. Sci. . doi:10.1073/pnas.1614085114

Stephenson, D.B., Pavan, V., Bojariu, R., 2000. Is the North Atlantic Oscillation a random walk? Int.J.Climatol.20,1-18. doi:10.1002/(SICI)1097-0088(200001)20:1<1::AIDJOC456>3.0.CO;2-P

Swingedouw, D., Mignot, J., Ortega, P., Khodri, M., Menegoz, M., Cassou, C., Hanquiez, V., 2017. Impact of explosive volcanic eruptions on the main climate variability modes. Glob. Planet. Change Submitted.

Swingedouw, D., Ortega, P., Mignot, J., Guilyardi, E., Masson-Delmotte, V., Butler, P.G., Khodri, M., Séférian, R., 2015. Bidecadal North Atlantic ocean circulation variability controlled by timing of volcanic eruptions. Nat. Commun. 6, 6545. doi:10.1038/ncomms7545

Trouet, V., Esper, J., Graham, N.E., Baker, A., Scourse, J.D., Frank, D.C., 2009. Persistent positive North Atlantic oscillation mode dominated the Medieval Climate Anomaly. Science 324, 78-80. doi:10.1126/ science. 1166349

Wanamaker, A.D., Butler, P.G., Scourse, J.D., Heinemeier, J., Eiríksson, J., Knudsen, K.L., Richardson, C. a., 2012. Surface changes in the North Atlantic meridional overturning circulation during the last millennium. Nat. Commun. 3, 899. doi:10.1038/ncomms1901

Wurtzel, J.B., Black, D.E., Thunell, R.C., Peterson, L.C., Tappa, E.J., Rahman, S., 2013. Mechanisms of southern Caribbean SST variability over the last two millennia. Geophys. Res. Lett. 40, 5954-5958. doi:10.1002/2013GL058458

Zhang,R.,2008. Coherentsurface-subsurfacefingerprint of the Atlantic meridional overturning circulation. Geophys. Res. Lett. 35, L20705. doi:10.1029/2008GL035463 